\title{
RESEÑA: SILLAS EN LA FRONTERA \\ MUJERES, TEATRO Y MIGRACIONES. \\ CONCEPCIÓN FERNÁNDEZ SOTO (EDICIÓN E \\ INTRODUCCIÓN $)^{1}$
}

\author{
Francisco Oscar Checa Fernández ${ }^{2}$
}

Concepción Fernández Soto (edición e introducción). Sillas en la frontera. Mujeres, teatro y Migraciones. Almería: Edual, 2018. Colección "Migraciones y Relaciones Interculturales". ISBN: 978-84-17261-40-5.

"De mujeres, cuerpos y fronteras"

Sillas en la frontera es una antología que recoge veintidós piezas breves de dramaturgas contemporáneas de diferentes procedencias geográficas y nacionales. Todas giran en torno a las nociones de tránsito (del viaje humano sempiterno), de frontera (de los límites, naturales y artificiales) y esperas (reflejadas en la imagen de esas sillas que dan cuerpo al título). Es, sin lugar a dudas, una obra única en su género.

Todas ellas son autoras de muy diversas latitudes, de distintas generaciones, con inquietudes similares, también diferentes, con un imaginario propio, con mundos simbólicos y horizontes de expectativas tan diversas como ellas mismas, con ganas de

\footnotetext{
${ }^{1}$ Fecha de recepción: 10/12/2020.

Fecha de aceptación: 11/12/2020.

2 Doctorando en el Programa de Lenguas, Textos y Contextos, Universidad de Granada; $\square$ francheca@gmail.com.
} 
construir/deconstruir los valores de la sociedad de hoy -y del mañana- y con la imperiosa responsabilidad de hacerse oír.

Algo hay en ellas que las vertebra, como muy bien señala la editora de la obra, la Dra. Fernández Soto: todas han sido interpeladas por la experiencia del fenómeno migratorio, no solo por lo que les cuentan o han leído, algunas desde la deuda emocional familiar (hijas o nietas de inmigrantes), otras desde su propia experiencia migratoria (a veces en una posición transnacional), y siempre desde el abordaje artístico y el compromiso ético -y estético- como el débito inquebrantable de ser ciudadanas activas, en este mundo de gritos anónimos, aunque también desde sus propios silencios. Dramaturgas de suelo inquieto que escriben contra el archivo. Así las denomina la editora de la obra. Mujeres que comparten territorios desde su diversidad.

Sus textos dialogan con otros textos, como dice J. Kristeva, y pertenecen a la categoría aristotélica de cívicos, que no es sino la cualidad moral que fomenta la responsabilidad y que garantiza los valores esenciales de nuestra sociedad. Por ello, muy por encima de lo que explícita -o implícitamente- denuncien, los suyos son discursos abiertos, múltiples y solidarios, resonando más allá de sus confines regionales y nacionales.

Las protagonistas de estas calas dramáticas son personas a punto de partir, detenidas en fronteras o refugiadas, literatas, filósofas, mujeres de radio, presas políticas o desaparecidas. Mujeres de todas las edades, blancas y negras. De todas las categorías sociales, reinas y plebeyas. Seres humanos de todos los confines de la tierra, de todas las épocas, unas conocidas, otras anónimas.

Desde la contemplación a la acción, desde el ayer y el hoy, esas protagonistas recorren espacios variados, reales y simbólicos, para vivir desmemorias, éxodos, exilios, 
fronteras, pérdidas traumáticas, torturas, refugios, guerras, dictaduras, muertes, estigmatización y xenofobia: cárceles, aeropuertos, centros de detención, cementerios, espacios fronterizos, barcos sin puerto, a modo de mares de Caronte, son los no-lugares que señala M. Augé, pero también lugares de memoria, como denomina P. Nora a los espacios simbólicos, que no son sino aquellos que dejan rastros y rememoran una memoria trágica colectiva. No nos cabe duda del papel que en estos textos juegan los contornos de la memoria, tanto en lo personal como lo colectivo: memoria histórica como esperanza de reconstrucción del pasado y proyección hacia el futuro.

El volumen que, por cierto, inaugura la colección de la Edual "Migraciones y Relaciones interculturales", se abre con un oportuno Prólogo, a cargo de la Dra. Rossana Fialdini Zambrano, profesora de la University of South Carolina; su síntesis es muy acertada y puede sintetizarse en el mismo título: "De fronteras y puentes. Una antología de teatro de mujeres".

Una amplia "Introducción", muy necesaria, presenta y explica el porqué de esta obra. Su editora, la profesora Fernández Soto, enfoca las veintidós piezas teatrales en el amplio marco de las migraciones internacionales, como tema clave de nuestro tiempo y su abordaje a través del arte y la literatura, y cuyo trabajo editorial tiene su origen en otra publicación anterior, de 2016, Los mares de Caronte. Diecisiete calas dramáticas sobre migraciones, publicada en Madrid, Editorial Fundamentos y editada junto al Dr. F. Checa, antropólogo de la Universidad de Almería. Todas las dramaturgas, según sabemos por esta introducción, fueron invitadas por la editora, teniendo en cuenta sus trayectorias y temáticas abordadas a lo largo de los años. Han sido elegidas de una amplia nómina y con la pretensión de que estuvieran representados un buen número de países e idiomas. Se publican en los idiomas originales de sus autoras, como el árabe, el inglés, el francés o el italiano, además del español. 
¿Qué se ofrece al lector en Sillas en la frontera? Son calas dramáticas especialmente significativas, enmarcadas en una dimensión globalizada e inclusiva; todas comparten un rasgo fundamental, ya que se centran en el poder y los efectos nefastos que se manifiestan en la concreción material o simbólica de las distintas fronteras a las que cada una refiere. Barreras legales que los estados han ido levantando para separar a los que tienen derechos de ciudadanía de los que no.

Magníficos ejemplos los de "Una silla en la frontera", de Bahira Abdulatif, o "María Zambrano", de Lola Blasco. "En un lugar de nadie", de Diana de Paco, “Aquarius", de Safaa Fathy, o "Los Girasoles de Van Gogh”, de Marcela Terra, hablan de esa experiencia personal de mujeres en tránsito, al tiempo que nos remiten a esta acuciante realidad, mil veces repetida a través de los medios de comunicación y que remiten a un presente dramático. Presente que ha sido actualidad siempre desde el pasado, cuando los mismos pueblos que hoy rechazan a los refugiados en otro tiempo no lejano huyeron de otras guerras suyas, de la misma hambre, de las mismas atrocidades de sus regímenes dictatoriales: es la historia con los mismos sufrimientos y destierros humanos. Centradas en el caso de Latinoamérica, las protagonistas de "Mientras la quietud", de Teresita Galimany, y "Punto de no retorno”, de Acoyani Guzmán, lo resumen a la perfección.

Hay, además, otras calas que nos enseñan las típicas barreras sociales y simbólicas que son el color de la piel, la etnicidad y el género. Estas barreras dirigen sus dardos hacia el cuerpo de la mujer. Buenos ejemplos son "No es país para negras", de Silvia Albert Sopale, "Here and Elsewhere", de Nora Amin, o "Yo, la Virreina. Yo, la mujer" y "La mujer y la radio a ambas orillas de una guerra", ambas de Antonia Bueno. Mujeres encadenadas, como en "Hamed y yo", de Diana de Paco, "María Teresa León, Rosa fría, patinadora de las estrellas ”, de Concha Fernández, "Carolina, he contado las manchas del 
leopardo hasta llegar a la luna", de Eva Hibernia, y "Torniquete", de Eva Cristina Vásquez, "Ella en familia", de Patricia Zangaro.

No obstante, también hay testimonios de esas mujeres con la fortaleza necesaria para derribar las barreras de la hegemonía patriarcal y, en su reafirmación, dominar su destino. Lo consiguen haciendo de la frontera un espacio de encuentro. Son las protagonistas de "Fragmentos de luz", de Diana Chery-Ramírez, "Atargatis (Tragicommedia mediterranea)", de Patrizia Monaco, o "De la necesidad y la esperanza", de Gracia Morales.

No faltan tampoco quienes dibujan a esas mujeres que desean derribar los muros de la incomprensión y las barreras culturales. Ahí se encuentran quienes protagonizan "Diario de una prófuga, de Juana Escabias, o "Pour le meilleur", de Marie-Françoise Rovati-Elhouini.

Finalmente, no son ajenas las fronteras y barreras llenas de dolor y muy traumáticas, es el caso de "The New World", de Lee Patton Chiles, cuyas protagonistas, tres mujeres procedentes de Afganistán, Bosnia y Congo, se ven obligadas a escapar de las atrocidades, los infiernos y las guerras de sus países, anteponiendo como escudos sus mismos cuerpos.

Ahora bien, si las obras dramáticas que componen este volumen despliegan una gran variedad temática, también aparecen distintas formas dramatúrgicas de enfrentarse al drama: van desde el monólogo único a los cruzados, pasando por el diálogo, hasta los relatos fragmentados, que incluyen apoyos visuales y musicales.

Tras cada particular estrategia comunicativa, todas las obras comparten un último objetivo común: acercar a los lectores/espectadores a la reflexión sobre un tema tan de 
actualidad como son los flujos migratorios y la otredad, adobadas con una imprescindible perspectiva de género.

También Sillas en la frontera es una obra magníficamente maquetada. A la ilustración de la cubierta, de Pepa Cobo, le acompañan otras para las diferentes calas, de la propia Cobo, de Letizia Irego, Sandra C. Pagura, Raquel Carro, de Modesto Molina y el chileno Santiago "Chago" Morales (in memoriam).

Estas Sillas... me traen a la memoria la canción de Raimon, "Al vent", que en sus primeras estrofas se le oye cantar gritando: “¡Al vent, la cara al vent, el cor al vent, les mans al vent, els ulls al vent, al vent del món. I tots, tots plens de nit buscant la llum, buscant la pau, buscan a déu, al vent del mon!" 